\title{
Prospecção de tecnologias para a aquicultura em feiras virtuais
}

\author{
Prospecting technologies for aquaculture in virtual fairs \\ Tecnologías de prospección para la acuicultura en ferias virtuales
}

Recebido: 27/01/2022 | Revisado: 31/01/2022 | Aceito: 02/02/2022 | Publicado: 18/02/2022

\author{
Mariana Soares \\ ORCID: https://orcid.org/0000-0003-1716-2164 \\ Embrapa Pesca e Aquicultura, Brasil \\ E-mail: marisoares23@hotmail.com \\ Daniele Klöppel Rosa Evangelista \\ ORCID: https://orcid.org/0000-0002-3874-9944 \\ Embrapa Pesca e Aquicultura, Brasil \\ E-mail: daniele.rosa@embrapa.br \\ Diego Neves de Sousa \\ ORCID: https://orcid.org/0000-0003-3124-5150 \\ Embrapa Pesca e Aquicultura, Brasil \\ E-mail: diego.sousa@embrapa.br
}

\section{Resumo}

Este estudo tem como objetivo prospectar as inovações tecnológicas apresentadas em feiras virtuais para a aquicultura e identicar os segmentos que mais se destacam para subsidiar a produção em cativeiro de camarões e peixes. O estudo prospectivo foi desenvolvido a partir da compilação de informações coletadas em duas feiras virtuais realizadas em 2020: Aqua Expo El Oro Online e International Fish Congress Brasil Digital. Dentre os resultados obtidos, identificaram-se segmentos que ofertaram produtos com alto know-how direcionados às novas tendências de cultivos. Destacou-se o segmento de nutrição e saúde animal, com uma ampla oferta de insumos, bem como tecnologias voltadas para alimentação automatizada em viveiros, demonstrando a importância nutricional para o enfretamento de enfermidades na produção aquícola. Ainda, os eventos apresentaram palestras com importantes profissionais da área da aquicultura que relataram os impactos da pandemia de Covid-19 no comércio internacional para o setor.

Palavras-chave: Prospeç̧ão tecnológica; Feira tecnológica; Comunicação para transferência de tecnologia.

\begin{abstract}
This study aims to explore the technological innovations presented in aquaculture virtual fairs and to identify the segments that stand out the most to subsidize the captive production of shrimp and fish. The prospective study was developed from the information compilation collected at Aqua Expo El Oro Online and International Fish Congress Brasil Digital, both fairs held in 2020. Among the results obtained, segments were identified that offered products with high know-how directed to new crop trends. The animal nutrition and health segment stood out, with a wide supply of inputs, as well as technologies aimed at automated feeding in nurseries, demonstrating the nutritional importance for coping with diseases in aquaculture production. In addition, the events featured lectures with leading aquaculture professionals who reported on the impacts of the Covid-19 pandemic on international trade for the sector.
\end{abstract}

Keywords: Technological prospecting; Technological fair; Communication for technology transfer.

\section{Resumen}

Este estudio tiene como objetivo prospectar las innovaciones tecnológicas presentadas en ferias virtuales para la acuicultura e identificar los segmentos que más se destacan para subsidiar la producción en cautiverio de camarones y peces. El estudio prospectivo se desarrolló a partir de la recopilación de información recolectada en dos ferias virtuales realizadas en 2020: Aqua Expo El Oro Online e International Fish Congress Brasil Digital. Entre los resultados obtenidos, se identificaron segmentos que ofrecían productos con alto know-how orientados a las nuevas tendencias de cultivo. Se destacó el segmento de nutrición y salud animal, con una amplia oferta de insumos, así como tecnologías destinadas a la alimentación automatizada en estanques, demostrando la importancia nutricional para el combate de enfermedades en la producción acuícola. Asimismo, los eventos contaron con conferencias con importantes profesionales del área acuícola quienes informaron sobre los impactos de la pandemia del Covid-19 en el comercio internacional para el sector.

Palabras clave: Prospección tecnológica; Feria tecnológica; Comunicación para la transferencia de tecnología. 


\section{Introdução}

A produção de camarões marinhos vem sendo representada principalmente pela criação da espécie Litopenaeus vannamei, conhecida popularmente como camarão-branco-do-Pacífico (Soares, 2021). Esta espécie possui pacote tecnológico bem desenvolvido e apresenta bom desempenho zootécnico para sua criação em cativeiro (Soares, 2019). Entre os principais países produtores de crustáceos, incluindo a espécie mencionada, destacam-se a China, Vietnã, Indonésia, Índia e Equador, com o Brasil ocupando o $11^{\circ}$ lugar na produção mundial (Fao, 2018) (Figura 1).

Figura 1 - Principais países produtores de crustáceos marinhos.



Fonte: Fao (2018).

O Equador é o quinto maior produtor mundial de crustáceos, sendo o setor camaroneiro correspondendo a mais de $95 \%$ da aquicultura no país, contribuindo de forma significativa na geração de emprego e renda (Fao, 2005; Fao, 2018; Fao 2020b). A carcinicultura neste país iniciou-se em 1970, nas províncias de El Oro e Guayas, onde a disponibilidade de salitre e pós-larvas de camarão tornaram lucrativa a atividade na região. Hoje o setor é o segundo mais importante no país, ficando atrás apenas do petróleo, o que corrobora com a importância do segmento para a economia equatoriana (Fao, 2005).

O país foi um dos primeiros da América Latina a sofrer as consequências da pandemia provocada pela Covid-19 (Altman et al., 2021). Conforme a população adoecia, sua economia também começou a sofrer os efeitos em todos os setores. No caso do setor camaroneiro, este conseguiu manter parte de suas operações ativas, mas foi um dos mais atingidos entre as exportações no país. O Equador já vinha enfrentando outro problema neste setor, pois desde setembro do ano de 2019 vinha tentando se recuperar da suspensão da exportação de camarões para a China, devido as possíveis remessas de camarões contaminados pela doença da mancha branca (Lozano, 2020).

Entre as estratégias adotadas para o enfrentamento das enfermidades na carcinicultura estão a interiorização dos cultivos em águas com baixa salinidade e redução nas densidades de cultivo, permitindo uma produtividade satisfatória das fazendas (Roy et al., 2010). Essa estratégia de cultivo adota no Equador mantém o país em destaque quanto à produção do camarão marinho L. vannamei, ainda muito superior ao volume produzido no Brasil (Figura 2). 
Figura 2 - Comparativo da produção de camarão marinho entre Brasil e Equador no período de 2010 a 2018.

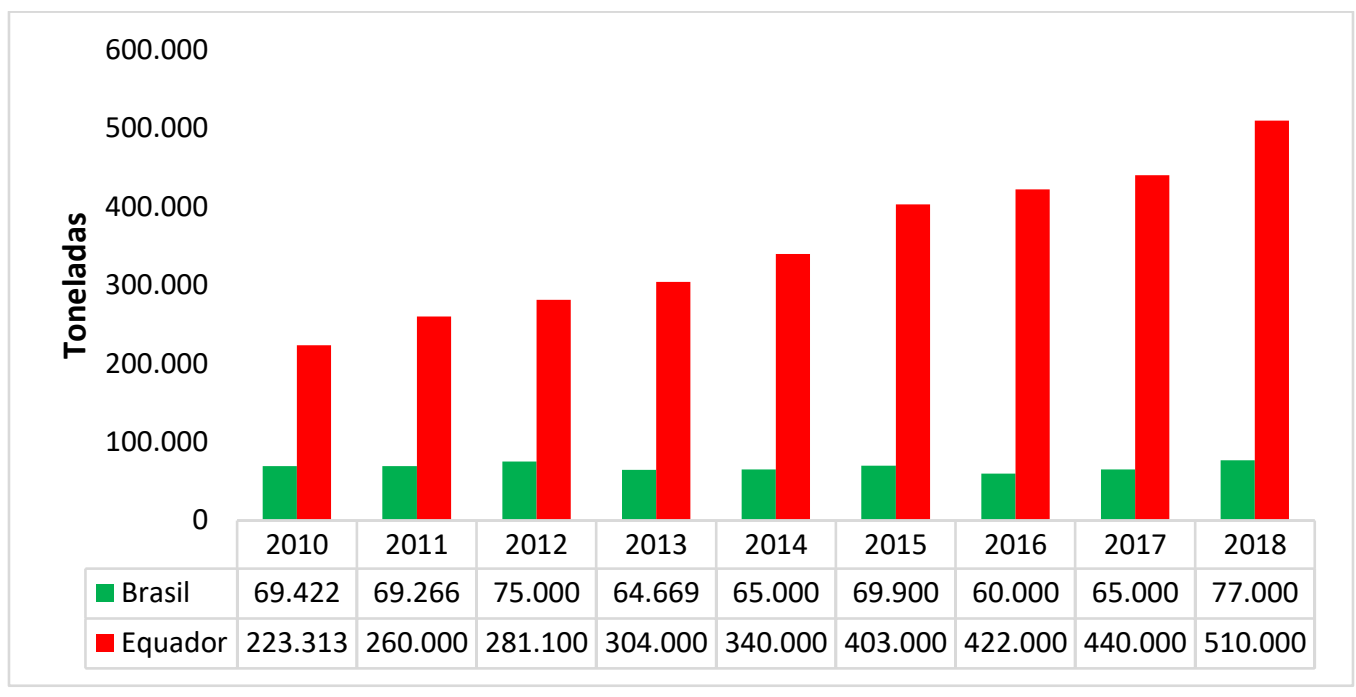

Fonte: Adaptado de Fao (2020)a e Abcc (2020).

A criação de camarões marinhos em regiões mais afastadas do litoral, com a utilização de águas subterrâneas devidamente salinizadas e livre de patógenos específicos comuns à água do mar, proporciona maior biosseguridade aos sistemas de cultivo e vem sendo adotada com maior frequência também no Brasil (Kubtza, 2019). Para que esses modelos sejam amplamente utilizados, instituições públicas e privadas têm desenvolvido tecnologias que auxiliam na adaptação dos camarões a novos ambientes, proporcionando desempenho zootécnico semelhante aos alcançados nos cultivos praticados nas regiões costeiras.

Em vista disso, as feiras tecnológicas são ambientes propícios para se conhecer o lançamento de tecnologias e também avaliar o grau de aceitação e adaptação de tecnologias já desenvolvidas no exterior. Como exemplo, a Feira Nacional do Camarão (Fenacam) realizada anualmente no Nordeste do Brasil, um evento técnico-científico e empresarial de referência para a cadeia da aquicultura e da carcinicultura nacional e latino-americana, conduzido de forma a facilitar a interação entre carcinicultores, aquicultores, palestrantes, congressistas e expositores.

Contudo, com a situação inesperada vivida mundialmente devido a pandemia da Covid-19, os eventos presenciais foram fortemente afetados, sendo necessário a adaptação à nova realidade apresentada. Uma das estratégias encontradas foi a realização de eventos em formato exclusivamente virtual, promovendo a interação da cadeia produtiva sem comprometer a saúde dos participantes e, assim, evitando a contaminação pelo contato pessoal.

Com isso, entre os dias 26 e 27 de agosto de 2020 foi realizada a Aqua Expo El Oro Online, um evento totalmente virtual para conectar os públicos de interesse mediante atividades de conferências, painéis e foros de discussões, ditados por reconhecidos expositores internacionais e locais com o intuito de ajudar a sustentar a cadeia da aquicultura em tempos de crise sanitária (Figura 3). 
Figura 3 - Logo do evento Aqua Expo El Oro Online.

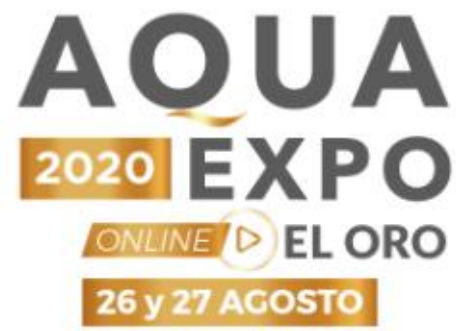

Fonte: Autores.

A Aqua Expo é uma feira que ocorre tradicionalmente no Equador, promovendo melhorias contínuas nas práticas de produção sustentável do camarão para aprimorar sua competitividade. Este ano, expositores nacionais e estrangeiros participaram do ciclo de conferências e os participantes tiveram a oportunidade de interagir com os conferencistas por meio de perguntas através dos chats. O evento também conectou os participantes com as últimas inovações tecnológicas da área, em que os expositores apresentaram suas tecnologias para o mercado do camarão. Os participantes puderam navegar pela feira virtualmente e interagir por mensagens e chamadas de vídeo com os expositores, tirando dúvidas, se informando das tecnologias oferecidas e realizando negócios.

Seguindo a mesma tendência e as medidas exigidas pelo atual cenário mundial, o Internacional Fish Congress \& Fish Expo Brasil (IFC) também foi realizado de forma virtual entre os dias 01 a 03 de dezembro de 2020 (Figura 4). O evento teve como objetivo unir todos os atores participantes dos elos da cadeia produtiva, sendo constituído por palestras com especialistas das diferentes áreas da aquicultura, divulgação de trabalhos científicos e também por uma feira tecnológica virtual, apresentando as últimas inovações tecnológicas do setor. Os participantes puderam navegar pela feira virtual, interagir com os expositores e conhecer um pouco mais das inúmeras tecnologias voltadas para o setor da aquicultura.

Figura 4 - Logo do evento IFC Brasil Digital.

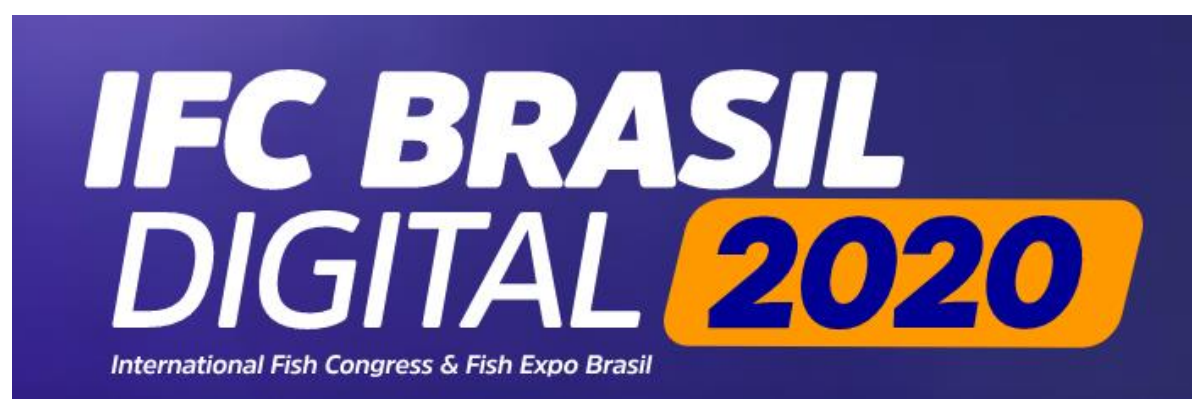

Fonte: Autores.

Neste contexto, o objetivo deste trabalho foi prospectar as inovações tecnológicas apresentadas nas feiras virtuais, Aqua Expo El Oro Online e no IFC Brasil Digital, como forma de categorizar os principais segmentos presentes nesses eventos, identificando o segmento de maior destaque em ambas as feiras e apresentar um portfólio das inovações oferecidas para o setor da aquicultura. Ainda, contribuir com informações que auxiliem no desenvolvimento de atividades da Empresa Brasileira de Pesquisa Agropecuária (Embrapa) atendendo às demandas da carcinicultura marinha nacional e promovendo a sustentabilidade do setor. 


\section{Metodologia}

No estudo prospectivo virtual realizado na Aqua Expo El Oro Online e no IFC Brasil Digital foram identificadas as tecnologias dos expositores participantes das feiras e possíveis alternativas para problemáticas do atual cenário da carcinicultura. A escolha desses dois eventos é dada a sua representatividade para o setor e por ter sido eventos ocorridos de forma virtual no ano de 2020.

Para isso, feiras virtuais foram acessadas, cujos estandes de cada empresa expositora disponibilizaram informações que auxiliaram na execução das atividades de prospecção tecnológica. As informações foram coletadas entre os dias 26 e 30 de agosto (Aqua Expo Oro Online) e de 01 a 03 de dezembro (IFC Brasil Digital) de 2020. A partir desse levantamento, as empresas expositoras foram categorizadas em diferentes segmentos da aquicultura, a fim de facilitar a identificação e sua representatividade na feira e também como forma de realizar uma amostra representativa desta pesquisa.

Ainda, os eventos contaram com a participação de conferencistas renomados na área da aquicultura mundial. Os conteúdos das palestras foram selecionados pela organização do evento com intuito de apresentar temas relacionados ao aprimoramento de protocolos de cultivo, boas práticas de manejo, enfermidades de importância para a aquicultura, melhoramento genético, sistemas de cultivo inovadores, mercado interno e externo de pescado, marketing para aquicultura, dentre outros em voga. As palestras em ambos os eventos foram direcionadas para o público da aquicultura em geral, proporcionando conhecimento sobre diferentes espécies cultivadas comercialmente e disponibilizando informações que contribuíram para a prospecção tecnológica realizada nesse trabalho.

\section{Resultados e Discussão}

A carcinicultura marinha é um segmento de relevância para a economia do Brasil e do Equador, com geração de renda, emprego e grande oportunidade de negócios. Ainda assim, ambos os países vêm há anos convivendo com enfermidades bacterianas e virais que acometem a produção, porém têm adotado estratégias de cultivo que proporcionam condições satisfatórias para os produtores de camarões e que buscam continuamente por tecnologias que mantenham o desenvolvimento do setor (Nunes \& Feijó, 2017; Ponse, 2019).

Diante disso, a captação de tecnologias que minimizem os riscos na produção contribui para a tomada de decisões dos diversos agentes envolvidos em todos os elos da cadeia produtiva, podendo nortear as pesquisas a serem desenvolvidas por instituições públicas e privadas, bem como auxiliando a solucionar tais gargalos na produção. Desta forma, este estudo prospectivo buscou categorizar e quantificar a oferta de tecnologias de empresas que atuam diretamente no desenvolvimento sustentável do setor, identificando o segmento com maior destaque em ambas as feiras.

Através das visitas virtuais as feiras, observou-se a oferta de produtos com alto know-how, insumos e novas tecnologias, demonstrando que existe a intenção por parte do setor em produzir com segurança sanitária e voltado para uma gestão profissionalizada.

Em ambas as feiras, os segmentos identificados em comum foram de nutrição e saúde animal, automação para aquicultura e maquinário para beneficiamento de pescado (Figuras 5 e 6). Na Aqua Expo El Oro Online mais dois segmentos foram identificados. Citam-se os meios de comunicação científica e tecnológica e produção sustentável de camarão, representado por um grupo de empresas certificadas com foco nos indicadores de impactos ambientais e sociais. No IFC Brasil Digital outros segmentos também foram observados, como a proposição de vacinas para peixes, produção de alevinos e beneficiamento de tilápias. 
Figura 5 - Quantitativo de empresas expositoras de serviços e produtos na Aqua Expo El Oro Online.

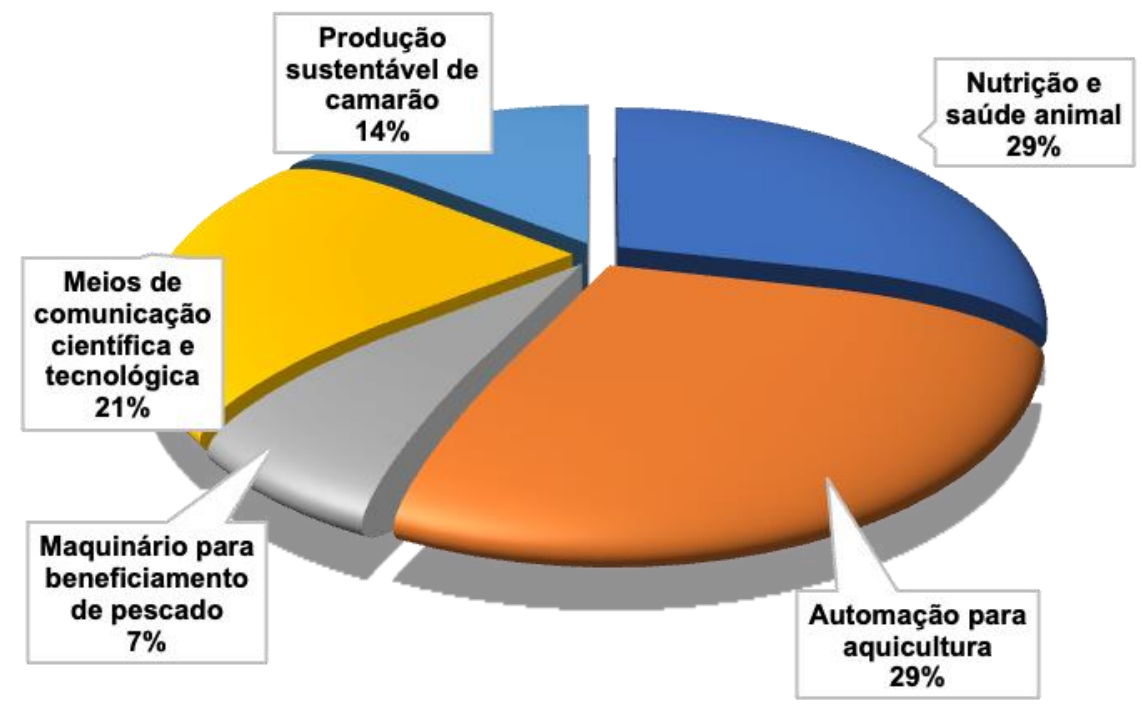

Fonte: Dados da pesquisa (2020)

Figura 6 - Quantitativo de empresas expositoras de serviços e produtos no IFC Brasil Digital.

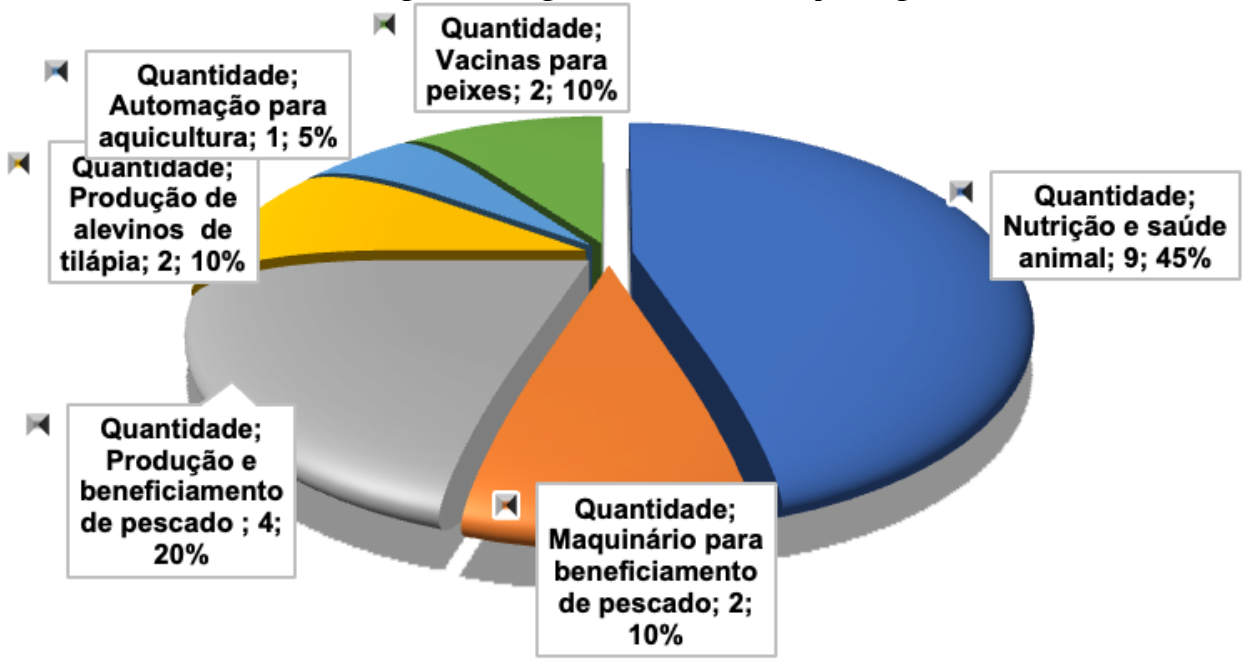

Fonte: Dados da pesquisa (2020).

O segmento com maior destaque nas feiras visitadas foi o de nutrição e saúde animal (Aqua Expo El Oro Online - 29 \% e Fish Expo Brasil - 45 \%), representado por empresas fortemente atuantes na produção de camarão marinho em toda a América Latina. As empresas expositoras apresentaram um portfólio de produtos bem diversificado, com rações específicas para diferentes densidades e fases de cultivo e inúmeros aditivos alimentares que auxiliam na saúde dos camarões, fortalecendo a sua imunidade (Quadros 1 e 2). 
Research, Society and Development, v. 11, n. 3, e37411326234, 2022

(CC BY 4.0) | ISSN 2525-3409 | DOI: http://dx.doi.org/10.33448/rsd-v11i3.26234

Quadro 1 - Empresas do segmento de nutrição e saúde animal expositoras na Aqua Expo El Oro Online.

\begin{tabular}{|c|c|c|c|}
\hline Empresa & Atuação & Portfólio & Destaques \\
\hline $\begin{array}{l}\text { DSM - Bright } \\
\text { Science }\end{array}$ & $\begin{array}{l}\text { Enzimas, vitaminas e minerais que } \\
\text { auxiliam na nutrição e saúde dos } \\
\text { camarões. }\end{array}$ & $\begin{array}{l}\text { Aditivos alimentares para dietas com } \\
\text { conteúdo proteíco de origem vegetal, } \\
\text { auxiliando na digestibilidade e no } \\
\text { complemento vitamínico-mineral. }\end{array}$ & $\begin{array}{c}\text { ROVIMIX®, STAY-C® 35, } \\
\text { ROVIMAX®, NX ROVIMIX®, E50 } \\
\text { (aditivos que melhoram a imunidade e saúde } \\
\text { dos camarões e peixes) }\end{array}$ \\
\hline $\begin{array}{l}\text { SKRETTING } \\
\text { (Nutreco } \\
\text { company) }\end{array}$ & $\begin{array}{l}\text { Rações específicas para cada fase } \\
\text { do cultivo, melhorando o } \\
\text { desempenho dos animais desde a fase } \\
\text { de larva até a fase de terminação. }\end{array}$ & $\begin{array}{c}\text { Rações que neutralizam os efeitos do } \\
\text { estresse. Lorica, masterline, setline, } \\
\text { Nature Wellness, Optiline, PL } \\
\text { Skretting e Vitalis. }\end{array}$ & $\begin{array}{c}\text { A linha Lorica é projetada para fortalecer o } \\
\text { camarão antes e durante um desafio } \\
\text { ambiental e bacteriano. }\end{array}$ \\
\hline $\begin{array}{l}\text { Nicovita } \\
\text { (Vitapro) }\end{array}$ & $\begin{array}{l}\text { Rações específicas para diferentes } \\
\text { fases do cultivo. Serviço de } \\
\text { assessoria para todas as etapas de } \\
\text { cultivo (avaliam os alimentadores } \\
\text { automáticos das fazendas e fazem um } \\
\text { plano alimentar para otimizar a } \\
\text { alimentação dos camarões). }\end{array}$ & $\begin{array}{l}\text { Portfólio diversificado de rações } \\
\text { nutricionais e funcionais, atuando na } \\
\text { nutrição e saúde dos camarões em } \\
\text { diferentes etapas de cultivo. }\end{array}$ & $\begin{array}{l}\text { Linha Katal - voltada para densidades } \\
\text { elevadas. Katal AD - para cultivos em baixa } \\
\text { salinidade, enriquecida com minerais para } \\
\text { proporcionar o balanço iônico ideal. Ambas } \\
\text { reduzem de } 10 \text { a } 15 \text { dias o tempo de } \\
\text { cultivo, garantindo maior crescimento em } \\
\text { menor tempo. }\end{array}$ \\
\hline Cargill & $\begin{array}{l}\text { Produção e processamento de } \\
\text { alimentos }\end{array}$ & $\begin{array}{l}\text { Linha Aquaxcel (rações extrusadas), } \\
\text { disponibilização promocional do } \\
\text { software iQShrimp para clientes e } \\
\text { rações purina, camaronex (ração } \\
\text { extrusada para sistemas de cultivo de } \\
\text { baixa densidade), Qua feed e Eco } \\
\text { feed (peletizada para crescimento). }\end{array}$ & $\begin{array}{l}\text { Linha Aquaxcel - tecnologia de extrusão, } \\
\text { produzindo partículas extrusadas muito } \\
\text { pequenas, uniformes e com alta eficiência } \\
\text { em sistema de } \\
\text { alimentação automática. Novo software } \\
\text { iQShrimp (monitoramento de dados em } \\
\text { tempo real para ajudar na tomada de } \\
\text { decisões durante o cultivo). }\end{array}$ \\
\hline
\end{tabular}

*DSM - https://www.dsm.com/latam/pt_BR/home.html

**Skretting - https://www.skretting.com/es-ec/

***Nicovita - https://www.nicovita.com.pe/SitePages/index.aspx

****Cargill - https://www.cargill.com/home. Fonte: Autores. 
Research, Society and Development, v. 11, n. 3, e37411326234, 2022

(CC BY 4.0) | ISSN 2525-3409 | DOI: http://dx.doi.org/10.33448/rsd-v11i3.26234

Quadro 2 - Empresas do segmento de nutrição e saúde animal expositoras na Fish Expo Brasil.

\begin{tabular}{|c|c|c|c|}
\hline Empresa & Atuação & Portfólio & Destaques \\
\hline Biorigin & $\begin{array}{c}\text { Produtos desenvolvidos com } \\
\text { processos biotecnológicos } \\
\text { exclusivos e controlados a partir de } \\
\text { cepas de levedura Saccharomyces } \\
\text { cerevisiae. São fontes naturais de } \\
\text { beta glucanas, mananas, proteínas, } \\
\text { aminoácidos, minerais orgânicos e } \\
\text { vitaminas do complexo B. }\end{array}$ & $\begin{array}{c}\text { Linha de atiditvos nutricionais } \\
\text { (Prebioticos) MACROGARD (Beta- } \\
\text { glucanos 1,3/1,6 purificados), } \\
\text { Biotide extra (RNA Nucleotideos } \\
\text { dieteticos) Active MOS (MOS de } \\
\text { cultura purificada) e Hyper Gen } \\
\text { (prebioticos superior) }\end{array}$ & $\begin{array}{l}\text { Prebioticos - Biotide extra (RNA } \\
\text { Nucleotideos dieteticos - energia } \\
\text { para crescimento) e Hyper Gen } \\
\text { (prebioticos superior- } 2 \text { geração de } \\
\text { MOS com efeito imunomulador). }\end{array}$ \\
\hline Guabi Aqua & $\begin{array}{l}\text { Rações específicas para diferentes } \\
\text { fases do cultivo. Serviço de } \\
\text { assessoria para os produtores e } \\
\text { avaliação do sistema de gestão da } \\
\text { produção na fazenda. }\end{array}$ & $\begin{array}{c}\text { Pira e Poti Evolution, com o selo } \\
\text { Gen Guabi indica uma ração com } \\
\text { aditivos naturais específicos para } \\
\text { cada espécie. Guabi Tech a primeira } \\
\text { ração extrusada para camarão. } \\
\text { Utilizam minerais orgânicos em suas } \\
\text { rações. }\end{array}$ & $\begin{array}{c}\text { SIGAD (nutrição + manejo + } \\
\text { genética). Mostra as melhorias que } \\
\text { necessitam ser feitas no manejo e a } \\
\text { ordem que precisam ser realizadas. } \\
\text { Esse acompanhamento é realizado } \\
\text { por um funcionário empresa. }\end{array}$ \\
\hline Socil & $\begin{array}{l}\text { Rações específicas para diferentes } \\
\text { fases do cultivo. }\end{array}$ & $\begin{array}{l}\text { Linha Laguna Camarão para a fase } \\
\text { inicial e engorda. Um portfólio } \\
\text { diversificado de rações para todas as } \\
\text { fases de cultivo, inclusive em baixas } \\
\text { salinidades. }\end{array}$ & $\begin{array}{c}\text { Rações para cultivo em baixa } \\
\text { salinidade. Laguna Camarão } 30 \\
\text { LS. }\end{array}$ \\
\hline Alltech & $\begin{array}{l}\text { Aditivos alimentares e fertilização } \\
\text { orgânica para viveiros. }\end{array}$ & $\begin{array}{c}\text { De uma melhor absorção de minerais } \\
\text { à uma melhor resistência contra } \\
\text { doenças, suas tecnologias } \\
\text { nutricionais apoiam a indústria da } \\
\text { aquicultura a superar desafios ligados } \\
\text { à saúde e desempenho de peixes e } \\
\text { camarões e à rentabilidade do } \\
\text { negócio. }\end{array}$ & $\begin{array}{c}\text { Aquate Shrimp um aditivo que } \\
\text { melhora a saúde intestinal e adsorve } \\
\text { bactérias patogênicas. Aquater } \\
\text { Fertilizer um simbiótico enzimático } \\
\text { que promove a fertilização orgânica } \\
\text { dos viveiros. }\end{array}$ \\
\hline $\begin{array}{l}\text { MSD Saúde } \\
\text { Animal/ Grupo } \\
\text { Merck \& CO }\end{array}$ & $\begin{array}{l}\text { Soluções tecnológicas para } \\
\text { promoção da saúde animal. }\end{array}$ & $\begin{array}{l}\text { Aquaflor } 50 \% \text { (premix), Aquavac }{ }^{\circledR} \\
\text { Strep (vacina inativada contra } \\
\text { Streptococcus agalactiae), } \\
\text { Aquavac }{ }^{\circledR} \text { Strep Sal (vacina } \\
\text { bivalente inativada contra } \\
\text { Streptococcus agalactiae) Biotipo } 1 \\
\text { (sorotipo Ia e III) e Omnicide } \AA \\
\text { (desinfetante rápido e de longa ação) }\end{array}$ & Vacinas da linha Aquavac®. \\
\hline SUPRA & $\begin{array}{l}\text { Rações específicas para diferentes } \\
\text { fases do cultivo. }\end{array}$ & $\begin{array}{l}\text { ACQUA line camarões, ACQUA } \\
\text { line e Anzol de ouro ACQUA line. }\end{array}$ & $\begin{array}{c}\text { ACQUA line camarões rações } \\
\text { extrusadas que promovem melhor } \\
\text { desempenho dos camarões. }\end{array}$ \\
\hline Phibro & Aditivos alimentares. & $\begin{array}{c}\text { TM - 700, PAQ-Gro }{ }^{\mathrm{TM}}, \mathrm{AB} 20 \AA \mathrm{e} \\
\text { PAQ-Protex } \AA .\end{array}$ & $\begin{array}{c}\text { PAQ-Protex® composto por } \\
\text { saponinas que promovem a } \\
\text { imunomodulação da parede celular } \\
\text { o que confere maior absorção de } \\
\text { nutrientes, principalmente ácidos } \\
\text { graxos e ação das células de defesa } \\
\text { no meio intracelular }\end{array}$ \\
\hline
\end{tabular}




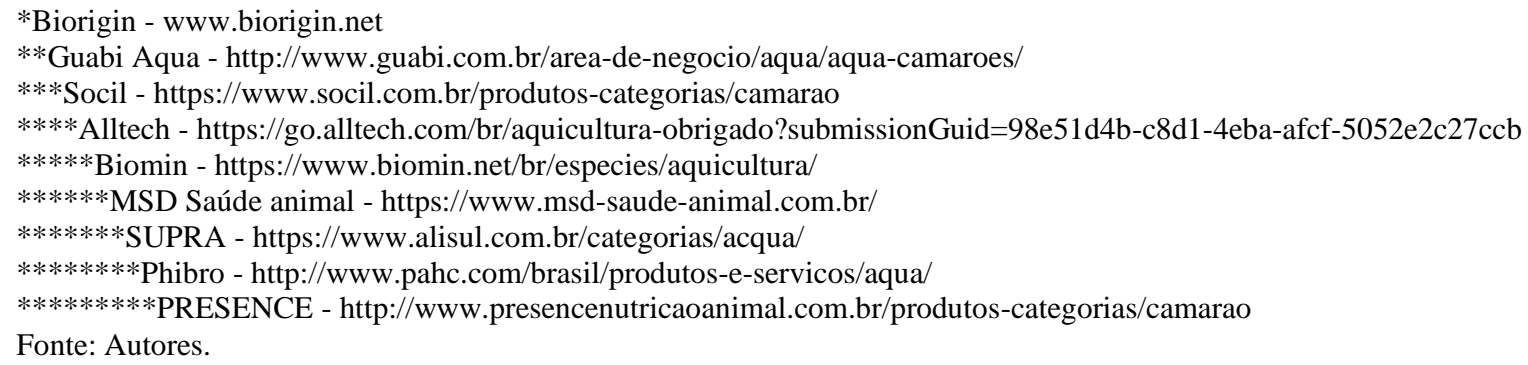

O mesmo resultado foi observado no estudo prospectivo realizado na Feira Nacional de Camarões (Fenacam) em 2019, em que o segmento com maior representatividade foi também o de nutrição e saúde animal. Durante a feira foram identificados 10 expositores apresentando tecnologias na área de nutrição e 12 expositores que comercializam aditivos alimentares para auxiliar na saúde animal. Neste estudo prospectivo, constatou-se que uma variedade de insumos e tecnologias estão disponíveis no mercado, porém devem ser utilizados quando desenvolvidos protocolos específicos para a realidade de cada sistema de cultivo empregado, no intuito de melhorar a produtividade nas fazendas (Evangelista et al., 2021).

Esses estudos fortalecem a importância da nutrição animal para o desenvolvimento do setor. A saúde e o bom desempenho dos animais de cultivo dependem em grande parte da alimentação fornecida, por isso a importância em se conhecer a composição da dieta ofertada e quais aditivos alimentares estão sendo aplicados (Glencross et al., 2007). Além disso, deve ser acompanhada por um planejamento estratégico de alimentação para cada sistema de cultivo empregado.

Uma boa nutrição animal é constituída por dietas balanceadas e suplementadas com aditivos alimentares que fortaleçam a imunidade dos animais para o enfrentamento de possíveis enfermidades no ambiente de cultivo. Dessa forma, o conhecimento sobre os componentes utilizados nas dietas e sua função para a nutrição animal se faz necessário para otimizar o manejo alimentar.

Em nosso trabalho, dentre as empresas do segmento de nutrição e saúde animal observou-se um quantitativo maior de expositores de rações para camarões e peixes, seguido pelo de vitaminas e minerais, probióticos e prebióticos, biorremediadores, nutracêuticos e enzimas. Abaixo segue a caracterização dos produtos ofertados nas feiras e seu papel na nutrição animal:

a) $\quad$ Ração: uma dieta que consiste apenas em um único ingrediente não é o suficiente para suprir todas as exigências nutricionais para o crescimento e desenvolvimento de determinada espécie, por isso os animais são alimentados com rações formuladas segundo as suas necessidades nutricionais. A formulação de rações consiste na adequação entre o cumprimento das exigências nutricionais da espécie e a escolha dos ingredientes que disponibilizam os nutrientes necessários para suprir essas exigências a um menor custo. Foi observado um portfólio bem diversificado com rações específicas para diferentes fases de cultivo, tais como larvicultura, transferência de pós-larvas, berçários, engorda e terminação, como também rações funcionais (nutrição e saúde), com aditivos alimentares que fortalecem o camarão antes e durante um desafio ambiental e/ou bacteriano. Ainda, rações para baixas densidades de cultivo e em baixa salinidade.

b) Vitaminas e minerais: são considerados micronutrientes, exigidos em pequenas quantidades na ração, porém essenciais para o normal crescimento, funções estruturais, fisiológicas e processos metabólicos dos animais. Importante seguir as recomendações nutricionais mínimas nas dietas para melhor desempenho dos animais em cativeiro. São oferecidos na ração em forma de premix vitamínico e mineral. Destaque nas feiras para a utilização de minerais orgânicos nas rações. 
Research, Society and Development, v. 11, n. 3, e37411326234, 2022

(CC BY 4.0) | ISSN 2525-3409 | DOI: http://dx.doi.org/10.33448/rsd-v11i3.26234

c) Probióticos: micro-organismos vivos que conferem benefícios à saúde do hospedeiro promovendo a alteração da microbiota intestinal, através da redução do crescimento de bactéria patogênica. Visando a substituição de medidas remediativas (antibióticos), promovendo um manejo preventivo ao surgimento de enfermidades. Podem também influenciar a produção de enzimas digestivas, melhorando a digestibilidade dos alimentos ofertados, otimizando a utilização de nutrientes e minerais presentes nas rações. São ministrados em pequenas quantidades na ração ou diretamente na água.

d) Prebióticos: carboidratos não-digeríveis que promovem/estimulam o crescimento de micro-organismos probióticos no trato digestório do hospedeiro. Administrados em pequenas quantidades na ração.

e) Biorremediador: micro-organismos e/ou seus metabólitos administrados na água de cultivo, visando acelerar a remoção e a biodegradação de contaminantes indesejáveis e a inibição de patógenos no ambiente de cultivo.

f) Nutracêuticos: alimentos ou parte de alimentos que apresentam benefícios à saúde, incluindo a prevenção e/ou tratamento de doenças. São administrados na ração em pequenas concentrações. Exemplos: nucleotídeos livres adicionados a dieta para auxiliar na resistência à doenças e minimizar os efeitos negativos causados pelo estresse em peixes e camarões; proteínas hidrolisadas utilizadas em pequenas concentrações na dieta melhorando a digestibilidade das rações e alterando a microbiota intestinal dos animais.

g) Enzimas: complexos enzimáticos são administrados na alimentação com a intenção de auxiliar no processo digestivo, promovendo a absorção dos nutrientes presentes na ração, muitas vezes indisponíveis devido à ausência de enzimas específicas no organismo do próprio animal. A adição de enzimas na ração de peixes e camarões melhora o desempenho zootécnico dos animais, melhorando a digestibilidade dos nutrientes e reduzindo os fatores antinutricionais presentes em muitos ingredientes de origem vegetal.

O portfólio de rações demonstra que o segmento está investindo fortemente em pesquisas que promovam o fortalecimento imunológico dos camarões para as possíveis adversidades durante as diferentes etapas de cultivo. As rações são balanceadas com premix vitamínicos e muitas passaram a utilizar minerais orgânicos, os quais estão mais biodisponíveis, sendo melhor aproveitados e promovendo melhor desempenho zootécnico dos animais em cativeiro. Ainda, com a inclusão de probióticos e/ou prebióticos, nutracêuticos e enzimas para melhorar a digestibilidade dos ingredientes nas rações, otimizando a utilização de uma maior diversidade de fontes proteicas de origem vegetal, e consequente absorção dos nutrientes, proporcionando fortalecimento nutricional e imunológico dos animais em cativeiro.

Em ambos os eventos se observou a importância e a tendência à automatização da aquicultura, sugerindo como um diferencial na produção de países mais desenvolvidos no setor. O segmento categorizado como automação para aquicultura consiste em empresas fornecedoras de alimentadores automáticos para viveiros de engorda de peixes e camarões, aeradores mecânicos, máquinas para transferência de peixes e camarões entre viveiros, misturadores de ração e softwares para alimentação automática. A automação da produção promove uma maior eficiência na produtividade, melhora o controle das condições ambientais de cativeiro, com a utilização de drones e softwares que mantem atualizada as informações necessárias para um manejo mais adequado e seguro na produção, com vistas a promover um aumento na produtividade de peixes e camarões. Além disso, muitas tecnologias tem favorecido a implementação de sistemas de cultivo intensivos, possibilitando o aumento nas densidades sem comprometer a segurança da produção em cativeiro. Isso demonstra que o agronegócio, em especial a aquicultura, está cada vez mais automatizado, confirmando o investimento em novas tecnologias que facilitem o seu desenvolvimento. 
Research, Society and Development, v. 11, n. 3, e37411326234, 2022

(CC BY 4.0) | ISSN 2525-3409 | DOI: http://dx.doi.org/10.33448/rsd-v11i3.26234

Como exemplo, cita-se o Equador que tem trabalhado com o planejamento estratégico alimentar das fazendas de engordas de camarão, adotando cada vez mais a utilização de alimentadores automáticos e softwares de alimentação. O que foi corroborado com o estudo prospectivo realizado na Aqua Expo El Oro Online e ainda pela feira Aqua Expo Guayaquil realizada, com uma pesquisa no site do evento, a qual contou com a presença de seis expositores de alimentadores automáticos para viveiros de engorda. Contudo, a automatização do setor exige um bom projeto de execução do sistema de cultivo, pois são investimentos elevados, que se não forem bem planejados podem não atender aos objetivos esperados.

Por fim, as ações estratégicas de marketing e por meio de mídias sociais de divulgação se mostraram viáveis no processo de atualização e disseminação das importantes tecnologias lançadas no ramo da aquicultura, contribuindo para o crescimento e fortalecimento da cadeia da aquicultura, além da minimização dos impactos no consumo global de pescado provocado pela crise sanitária da pandemia de Covid-19.

\section{Conclusão}

Feiras tecnológicas voltadas para a área da aquicultura são oportunidades para a interação entre produtores, fornecedores, distribuidores, pesquisadores e demais atores que integram a cadeia produtiva da aquicultura ao possibilitar a formação de redes de relacionamento para facilitar a geração e a transferência de tecnologia. Contudo, o cenário atual devido a pandemia provocada pela Covid-19 tem afetado a realização de eventos que promovam a troca de conhecimentos entre produtores, empresas e instituições públicas e privadas, exigindo que novas estratégias sejam adotadas para que o setor da aquicultura continue se atualizando em termos de inovação tecnológica. Uma alternativa foi a promoção de eventos na modalidade virtual, em que fosse possível acessar a feira de qualquer lugar do mundo e conhecer as inovações tecnológicas disponibilizadas.

Neste sentido, este documento contribui para compilar as inovações tecnológicas voltadas para o fortalecimento nutricional e imunológico de camarões e peixes criados em cativeiro disponibilizado em duas feiras da área, demostrando-se um segmento de relevância para o enfrentamento de enfermidades e consequente desenvolvimento do setor aquícola. Apesar das inovações tecnológicas com sistemas de cultivo que reduzam os riscos de contaminação por enfermidades de grande impacto econômico, tais como: o sistema de bioflocos e recirculação de água, verifica-se que a nutrição permanece sendo a principal maneira de minimizar as perdas provocadas por doenças na aquicultura. Isso porque o fornecimento de uma adequada ração fortalece imunologicamente os animais, preparando-os para possíveis adversidades no ambiente de cultivo.

O estudo ainda apresentou o possível diferencial tecnológico da carcinicultura equatoriana, estando entre esses aspectos o cuidado com o fornecimento de alimentos de alta qualidade e com a adoção de alimentadores automáticos e programas estratégicos de alimentação, sugerindo serem aspectos que fazem o país estar entre os principais produtores de camarão. Tratase, assim, de buscar o respeito principalmente no que tange as diferentes estratégias de cultivo, como alimentos específicos para criação em baixa salinidade, menores densidades e aplicação de aditivos alimentares.

Verificou-se, ainda, que os eventos virtuais trouxeram em suas palestras exemplos de países produtores de camarão e peixes, seus avanços na produção, os efeitos e impactos da pandemia de Covid-19 no comércio internacional de produtos aquícolas e a importância do fortalecimento da cadeia para incentivar o aumento do consumo de pescado em meio a crise global. Além disso, constatou a importância na realização de campanhas educativas para promover o empreendedorismo dos produtores, trabalhando com as questões de boas práticas de manejo, importância da nutrição para o bom desempenho dos animais e a realização de ações de marketing para os produtos gerados. Portanto, os resultados deste estudo prospectivo podem contribuir com o apoio na formulação de políticas públicas para a potencialização e integração do setor aquícola.

As informações aqui compiladas servem de suporte às instituições brasileiras privadas e públicas que desenvolvam 
Research, Society and Development, v. 11, n. 3, e37411326234, 2022

(CC BY 4.0) | ISSN 2525-3409 | DOI: http://dx.doi.org/10.33448/rsd-v11i3.26234

ações de inovação tecnológica e de capacitação para criação de espécies aquícolas comerciais, tornando o monitoramento das inovações um instrumento de apoio à tomada de decisão quanto às tecnologias em desenvolvimento, bem como projetos de PD\&I relacionados à temática da carcinicultura e piscicultura em andamento no Brasil e demais instituições parceiras internacionais e que atuam nesta temática.

\section{Agradecimentos}

Agradecemos pelo apoio financeiro do Banco Nacional de Desenvolvimento Econômico e Social (BNDES), da Secretaria de Aquicultura e Pesca do Ministério da Agricultura Pecuária e Abastecimento do Brasil (SAP-MAPA), da Empresa Brasileira de Pesquisa Agropecuária (Embrapa) e pela parceria com Conselho Nacional de Desenvolvimento Científico e Tecnológico (CNPq) ao projeto "BRS Aqua - Ações estruturantes e inovação para fortalecimento das cadeias produtivas da Aquicultura no Brasil".

\section{Referências}

ABCC. (2020). Produção Brasileira de Camarão Marinho Cultivado por Estado: dados reais de 2015 a 2019https://abccam.com.br/2020/10/producaobrasileira-de-camarao-marinho-cultivado/.

Altmann, P., Polo, R., King, K., \& Maldonado, M. R. (2021). Verdades y mentiras sobre la COVID-19 en Ecuador: ruptura de conocimientos y sus efectos sociales. (2021). Revista Sociedade e Cultura, 24, 1-32. 105216/sec.v24.e66048

Evangelista, D. K. R., Soares, M., Sousa, D. N., Belchior, E. B. \& Nascimento, M. S. N.(2021). Prospecção de ofertas tecnológicas e principais demandas da carcinicultura marinha brasileira. Cadernos de Ciência \& Tecnologia, 38(1):e26763.

Fao - Food and Agriculture Organization of United Nations. (2005). Visión general del sector acuícola nacional, Ecuador. http://www.fao.org/fshery/countrysector/naso_ecuador/es\#tcN70044.

Fao - Food and Agriculture Organization of United Nations. (2018). The state of World Fisheries and Aquaculture. Rome, Italy: FAO.

Fao - Food and Agriculture Organization of United Nations. (2020)a. Global Aquaculture Production 1950-2018. 2020. https://bit.ly/3L2ehIq

Fao - Food and Agriculture Organization of United Nations (2020)b. Software FishStatJ para séries temporais estatísticas de pesca e aquicultura FisherDivisão: FAO. https://www.fao.org/fishery/en/statistics/software/fishstatj/en

Glencross, B. D.; Booth, M.; \& Allan, G. L. (2007). A feed is only as good as its ingredients - a review of ingredient evaluation strategies for aquaculture feeds. Aquaculture Nutrition, 13, 17-34.

Kubtiza, F. (2019). A interiorização do L. vannamei no Brasil e os desafios no transporte de PL's e do cultivo intensivo com zero descarga de água. In: Feira Nacional De Camarão, 19., 2019, Natal. Manual do Congressista. ABCC, 2019. 54-58.

Lozano, G. (2020). Equador recorre a China para salvar setor de camarões da crise. https://dialogochino.net/pt-br/comercio-e-investimento-pt-br/36032equador-recorre-a-china-para-salvar-setor-de-camaroes-da-crise/.

Nunes, A. J. P., \& Feijó, R. G. (2017). O vírus da mancha branca e a convivência no cultivo de camarão marinho no Brasil. Panorama da Aquicultura, 27, $162,36-47$.

Ponse, N. (2019). Não deixe o mal entrar: prevenir, na carcinicultura, é mil vezes melhor do que remediar. Feed \& Food, ed. Especial aquicultura, 38-39, nov.

Roy, L. A., Davis, A. D., Saoud, C. A. P., \& Boyd, C. E. (2010). Shrimp culture in inland low salinity waters. (2010). Reviews in Aquaculture, 2, 191-208. https://doi.org/10.1111/j.1753-5131.2010.01036.x

Soares, M. (2019). Avaliação de hidrolisados proteicos de subprodutos de frango e suíno na nutrição do camarão-branco-do-Pacífico. 99 f. Tese (Doutorado em Aquicultura) - Universidade Federal de Santa Catarina, Florianópolis, SC.

Soares, M., Rezende, P. C., Schleder, D. D., Delgadillo-Diaz, M., Gullian-Klanian, M., \& Vieira, F. N. (2021). Protein hydrolysate of poultry by-product and swine liver in the diet of pacific white shrimp. (2021). Boletim do Instituto de Pesca, 47, 1-10. 